\title{
DISPARITAS PEMBANGUNAN EKONOMI ANTAR WILAYAH DI PROVINSI MALUKU UTARA
}

\author{
Aisa Mashud \\ Noortje M. Benu \\ Mex L. Sondakh
}

\begin{abstract}
The objective of this research is to assess the economic development disparities among districts and cities in North Maluku in 2010 - 2015 period. This research is motivated by the diversity of natural resources and demographic conditions, differences in income per capita and economic growth contained in each regency and town in North Maluku. As a result of these differences, the ability to increase economic development is different from one region to the other region. The data collected for two months from February to March 2017. The data used are PDRB per capita data, population data and economic growth data obtained from Central Bureau of Statistics of North Maluku Province. Analysis of data in the form of descriptive analysis presented in tabular form using Williamson Index analysis tool. The results showed that the economic development district and cities in the province of North Maluku during the period 2010 - 2015 continues to inequality, where the data is used proved that there are significant differences among the districts and cities in North Maluku. Results proficiency level could be seen clearly when analyzed by Williamson Index which indicates that the rate of economic development was still classified inequality on inequality of economic development. This was due to the diversity of potential and natural resources among districts and cities that led to per capita income and economic growth becomes different resulting imbalance of economic development.
\end{abstract}

Keywords: disparity, economic development, North Maluku Province.

Penelitian ini bertujuan untuk mengkaji disparitas pembangunan ekonomi antar Wilayah di Provinsi Maluku Utara periode tahun 2010 - 2015. Penelitian ini dilatar belakangi oleh adanya keragaman potensi sumber daya alam dan kondisi demografi, perbedaan pendapatan per kapita dan pertumbuhan ekonomi yang terdapat pada masing-masing daerah di Maluku Utara. Akibat dari perbedaan tersebut, kemampuan suatu daerah untuk meningkatkan pembangunan ekonomi menjadi berbeda antara suatu daerah dengan daerah lainnya. Pengumpulan data berlangsung selama dua bulan sejak bulan Februari sampai Maret 2017. Data yang digunakan berupa data PDRB per kapita, data jumlah penduduk dan data pertumbuhan ekonomi yang diperoleh dari Badan Pusat Statistik Provinsi Maluku Utara. Analisis data berupa analisis secara deskriptif yang disajikan dalam bentuk tabel dengan menggunakan alat analisis Williamson Index. Hasil penelitian menunjukkan bahwa pembangunan ekonomi Kabupaten/Kota di Provinsi Maluku Utara selama periode tahun 2010 - 2015 terus mengalami ketimpangan, dimana data yang digunakan membuktikan bahwa adanya perbedaan yang signifikan antar Kabupaten/Kota di Maluku Utara. Hasil tesebut dapat diketahui secara jelas setelah dianalisis dengan Indeks Williamson yang menunjukkan bahwa angka ketimpangan pembangunan ekonomi masih tergolong pada ketidak merataan pembangunan ekonomi. Hal ini dikarenakan adanya keragaman potensi dan sumber daya alam antar Kabupaten/Kota yang menyebabkan pendapatan perkapita serta pertumbuhan ekonomi menjadi berbeda sehingga terjadi ketimpangan pembangunan ekonomi.

Kata kunci: disparitas, pembangunan ekonomi, Provinsi Maluku Utara. 


\section{PENDAHULUAN}

\section{Latar Belakang}

Pembangunan daerah dapat diartikan sebagai sebuah proses dalam mencapai kemajuan yang lebih baik dari arah sebelumnya. Dalam konteks ini, pembangunan ekonomi menjadi prioritas utama. Hal ini dikarenakan dalam pembangunan ekonomi terdapat usaha untuk dapat mencapai kenaikan tingkat pendapatan, menyediakan kesempatan kerja, mengusahakan pembagian pendapatan supaya lebih merata dan mengurangi perbedaan dalam tingkat perkembangan dan pembangunan dan juga mengurangi tingkat ketimpangan pendapatan dan pembangunan antar wilayah (regional) agar proses pembangunan menjadi lebih seimbang.

Pada hakikatnya pembangunan perekonomian merupakan rangkaian kegiatan melalui perencanaan dalam rangka meningkatkan kesejahtraan masyarakat. Pembangunan ditujukan untuk peningkatan pendapatan masyarakat yang tidak lepas dari keberhasilan pembangunan ekonomi dan diukur dalam tingkat pertumbuhan ekonomi disuatu wilayah.

Salah satu indikator keberhasilan pembangunan ekonomi dari suatu dearah adalah pertumbuhan ekenomi. Pertumbuhan ekonomi adalah suatu proses peningkatan kapasitas produktif dari suatu perekonomian secarah keseluruhan dan terus-menerus atau berkesinambungan sepanjang waktu sehingga menghasilkan tingkat pendapatan yang semakin lama semakin besar (Pradjya, 2010).

Pertumbuhan pendapatan ekonomi harus di laksanakan secara komperensif dalam upaya terciptanya pemerataan hasilhasil pembangunan. Dengan demikian wilayah yang awalnya tidak produktif menjadi lebih produktif, yang akhirnya mempercepat pertumbuhan itu sendiri. Pertumbuhan ekonomi daerah yang berbedabeda intensitasnya akan menyebabkan terjadinya ketimpangan atau disparitas ekonomi dan ketimpangan pendapatan antar daerah (Sirojuzilam, 2008).

Disparitas pembangunan ekonomi terjadi karena banyak faktor-faktor penyebab diantaranya adalah sumber daya alam, sumber daya manusia, pemusatan kegiatan ekonomi disuatu wilayah/daerah, pertambahan stok kapital, jumlah penduduk, dan masih terfokusnya investasi di wilayah tertentu saja dan juga kualitas infrastruktur yang tidak merata antar wilayah. Disamping itu, keadaan geografis yang berbeda-beda antar daerah juga merupakan masalah yang menyebabkan disparitas pembangunan ekonomi antar wilayah (Irawan, 2012).

Provinsi Maluku Utara adalah salah satu Provinsi di Indonesia yang memiliki 8 Kabupaten (Kabupaten Halmahera Barat, Kabupaten Halmahera Timur, Kabupaten Halmahera Tengah, Kabupaten Halmahera Utara, Kabupaten Halmahera Selatan, Kabupaten Pulau morotai, Kabupaten Kepulauan Sula, Kabupaten Pulau Taliabu) dan Kota yaitu (Kota Ternate dan Kota Tidore).

Perkembangan Perekonomian di Provinsi Maluku Utara tercermin dengan adanya pola kemitraan antara pemerintah dan sektor swasta serta masyarakat dalam mengelola sumber daya yang tersedia untuk merangsang perkembangan kegiatan pembangunan ekonomi serta memperkancar pertumbuhan ekonomi dalam daerahnya yang tujuannya mengurangi ketimpangan pembangunan ekonomi antar Provinsi Maluku Utara (BPS, 2014).

Provinsi Maluku Utara memiliki beragam potensi ekonomi, dari sumber daya alam berbasis pertanian, kelautan dan pariwisata. Potensi ini diharapkan dapat diberdayakan secara maksimal sehingga meningkatkan perekonomian wilayah. Pertumbuhan ekonomi sebagai sasaran yang ingin dicapai Pemerintah Provinsi Maluku Utara harus bisa meningkatkan pendapatan perkapita dan menurunkan tingkat kemiskinan. 


\section{Rumusan Masalah}

Berdasarkan uraian sebelumnya, maka yang menjadi permasalahan yaitu, bagaimana disparitas (kesenjangan) pembangunan ekonomi antar wilayah di Provinsi Maluku Utara selama enam tahun terakhir (2010 2015) berdasarkan data PDRB per kapita dan pertumbuhan ekonomi antar wilayah Provinsi Maluku Utara.

\section{Tujuan Penelitian}

Tujuan penelitian adalah mengkaji disparitas pembangunan ekonomi antar wilayah di Provinsi Maluku Utara.

\section{Manfaat Penelitian}

Manfaat penelitian ini adalah:

1. Sebagai sumber informasi kepada para pengambil keputusan yaitu Pemerintah Provinsi Maluku Utara tentang daerah yang berpotensi perekonomian tinggi di Provinsi Maluku Utara.

2. Sebagai penambah wawasan bagi peneliti tentang cara menganalisis potensi daerah dalam suatu wilayah.

3. Sebagai bahan referensi bagi penelitian selanjutnya.

\section{METODOLOGI PENELITIAN}

\section{Waktu dan Tempat Penelitian}

Penelitian ini berlangsung dari bulan Februari sampai Maret 2017. Penelitian ini dilaksanakan di Provinsi Maluku Utara.

\section{Metode Pengumpulan Data}

Data yang digunakan dalam penelitian ini adalah data sekunder yang diperoleh dari BPS (Badan Pusat Statistik) dan BAPPEDA (Badan Perencanaan Pemerintah Dearah) Provinsi Maluku Utara dan publikasipublikasi yang lain yang dapat menunjang penelitian ini.

\section{Konsepsi Pengukuran Variabel}

Variabel yang diukur dan diteliti adalah:

1. PDRB per kapita Daerah Kabupaten/Kota di Provinsi Maluku Utara atas dasar harga konstan. PDRB per kapita yang diteliti dan diukur adalah terdiri dari 8 Kabupaten dan 2 Kota selama 2010-2015.

2. PDRB per kapita rata-rata Kabupaten/Kota di Provinsi Maluku Utara atas dasar harga konstan.

PDRB per kapita rata-rata seluruh Kabupaten/Kota di Provinsi Maluku Utara adalah penjumlahan seluruh nilai PDRB Kabupaten/Kota di bagi dengan jumlah Kabupaten/Kota yang ada di Provinsi Maluku Utara.

3. Jumlah Penduduk Kabupaten/Kota Provinsi Maluku Utara

Jumlah Penduduk daerah Kabupaten/Kota di Provinsi Maluku Utara terdiri dari jumlah penduduk Kabupaten Halmahera Barat, Halmahera Tengah, Kepulauan Sula, Halmahera Selatan, Halmahera Utara, Halmahera Timur, Pulau Morotai, Pulau Taliabu dan Kota Ternate dan Kota Tidore.

4. Jumlah Penduduk di Provinsi Maluku Utara Jumlah Penduduk Seluruh Kabupaten/Kota di Provinsi Maluku Utara adalah penjumlahan seluruh jumlah penduduk yang ada di Provinsi Maluku Utara.

5. Pertumbuhan ekonomi Kabupaten/Kota di Provinsi Maluku Utara

Angka Pertumbuhan ekonomi diperoleh dari persentase nilai PDRB.

\section{Metode Analisis Data}

Analisis yang digunakan dalam menghitung ketimpangan (disparitas) Pembangunan ekonomi antar daerah Kabupaten/Kota di Provinsi Maluku Utara adalah analisis secara deskriptif yang dalam bentuk tabel dengan menggunakan alat Analisis Indeks Williamson.

Ukuran ketimpangan pembangunan antar daerah atau antar wilayah yang mula-mula dilakukan adalah Indeks Williamson pada tahun 1966. Istilah Williamson Indeks sebagai penghargaan kepada pengguna awal indeks tersebut dalam mengukur ketimpangan antar wilayah (Sjafrizal, 2012).

$$
\mathrm{Vw}=\frac{\left.\sqrt{\sum_{\boldsymbol{i}=1}^{\boldsymbol{n}}(\boldsymbol{y} \boldsymbol{i}-\overline{\boldsymbol{y}})^{2}(\boldsymbol{f i}} / \boldsymbol{n}\right)}{\overline{\mathrm{y}}} \text { di mana } 0<\mathrm{Vw}<1
$$


Dimana

yi $=$ PDRB per kapita Kabupaten/Kota di Provinsi Maluku Utara

$\overline{\mathrm{y}}=$ PDRB per kapita rata-rata seluruh Kabupaten/Kota Provinsi Maluku Utar

fi $=$ Jumlah Penduduk Kabupaten/Kota

$\mathrm{n}=$ Jumlah Penduduk Provinsi Maluku Utara.

Kab. Halmahera Barat, Kab. Halmahera Timur, Kab. Halmahera Tengah, Kab. Halmahera Utara, Kab. Halmahera Selatan, Pulau Morotai, Kepulauan Sula, Pulau Taliabu dan Kota Ternate dan Kota Tidore.

Hasil dari Indeks Williamson adalah sebagai berikut : bila Vw memiliki angka 1 berarti tingkat kesenjangan makin tinggi dan bila $\mathrm{Vw}$ memiliki angka 0 berarti tidak ada kesenjangan ekonomi antar daerah Kabupaten/Kota di Provinsi Maluku Utara. Semakin besar indeks yang dihasilkan maka semakin besar pula tingkat kesenjangan antar daerah Kabupaten/Kota di Provinsi Maluku Utara.

\section{HASIL DAN PEMBAHASAN}

\section{Deskripsi Lokasi Penelitian}

Provinsi Maluku Utara dengan Ibu Kota Sofifi terletak diantara $3^{0}$ Lintang Utara $-3^{0}$ Lintang Selatan dan antara $124^{0}-129^{\circ}$ Bujur Timur. Sebelah Utara berbatasan dengan Samudra Pasifik, sebelah Timur Berbatasan dengan Laut Halmaherah, sebelah Selatan berbatasan dengan Laut Seram.

Luas Wilayah Maluku Utara adalah 132.631,09 $\mathrm{km}^{2}$ yang meliputi delapan Kabupaten dan dua Kota antara lain Kabupaten Halmahera Barat, Halmahera Tengah, Kepulauan Sula, Halmahera Selatan, Halmahera Utara, Halmahera Timur, Pulau Morotai, Pulau Taliabu dan Kota Ternate dan Kota Tidore.

\section{Jumlah Penduduk Kabupaten/Kota di Provinsi Maluku Utara}

Jumlah penduduk Maluku Utara hasil proyeksi penduduk tahun 2015 berjumlah 1.549.872 jiwa. Angka ini merupakan peningkatan dari tahun 2014 sebesar 1.535.970 jiwa, sementara jumlah penduduk pada tahun 2013 sebesar 1.519.014 jiwa meningkat dari tahun 2012 sebesar 1.501.739 jiwa sehingga dapat disimpulkan bahwa peningkatan jumlah penduduk akan dapat berpengaruh terhadap perekonomian yang ada karena sejumlah sumber daya penduduk diperlukan dalam proses pembangunan ekonomi (BPS MALUT, 2014).

\begin{tabular}{|c|c|c|c|c|c|c|c|}
\hline \multicolumn{8}{|c|}{$\begin{array}{r}\text { Tabel 1. Jumlah Penduduk } \mathrm{F} \\
\text { Tahun 2010-2015 }\end{array}$} \\
\hline \multirow[t]{2}{*}{ No. } & \multirow[t]{2}{*}{ Kabupaten/Kota } & \multicolumn{6}{|c|}{ Tahun (Jiwa) } \\
\hline & & 2010 & 2011 & 2012 & 2013 & 2014 & 2015 \\
\hline 1. & Halmahera Barat & 182017 & 182292 & 182818 & 195553 & 197755 & 198901 \\
\hline 2. & Halmahera Tengah & 74042 & 80134 & 80508 & 70693 & 71564 & 71530 \\
\hline 3. & Kepulauan Sula & 95002 & 95145 & 95525 & 100443 & 101575 & 101761 \\
\hline 4. & Halmahera Selatan & 130129 & 130290 & 130449 & 126100 & 127520 & 128732 \\
\hline 5. & Halmahera Utara & 172690 & 174455 & 176480 & 188904 & 191036 & 193906 \\
\hline 6. & Halmahera Timur & 82684 & 83200 & 83718 & 91553 & 92583 & 93857 \\
\hline 7. & Pulau Morotai & 74786 & 74892 & 74997 & 83834 & 84387 & 85171 \\
\hline 8. & Pulau Taliabu & 61576 & 61652 & 61781 & 63801 & 64516 & 64575 \\
\hline 9. & Temate & 424111 & 429149 & 434845 & 410481 & 415114 & 417843 \\
\hline 10. & Tidore & 174003 & 178226 & 180618 & 187652 & 189920 & 193956 \\
\hline
\end{tabular}

\section{Produk Domestik Regional Bruto Per Kapita Atas Dasar Harga Konstan Antar \\ Kabupaten/Kota di Provinsi Maluku Utara}

Berdasarkan data PDRB per kapita atas dasar harga konstan antar Kabupaten/Kota MALUT dapat tercermin bahwa dari tahun ke tahun PDRB per kapita MALUT terus megalami peningkatan.

Peningkatan perekonomian yang ada di Maluku Utara tidak lepas dari peran tiap Kabupaten/Kota yang ada melalui berbagai potensi dan kekayaan alam yang dimiliki di tiap Kabupaten/Kota Provinsi Maluku Utara. Perekonomian Provinsi Maluku Utara dapat dibuktikan dengan kinerja dari masing-masing daerah Kabupaten/Kota.

Kinerja perekonomian suatu wilayah pada periode tertentu bercermin dari angka Produk Domestik Regional Bruto (PDRB), seiring dengan meningkatnya perekonomian Maluku Utara, PDRB per kapita mengalami peningkatan signifikan, dimana untuk tahun 2014 sebesar 10,311 juta rupiah meningkat dibandingkan tahun 2013 yang mencapai 9,705 juta rupiah. Sementara pada tahun 2015 meningkat dengan total PDRB per kapita yaitu senilai 11,120 juta rupiah (BPS MALUT, 2014).

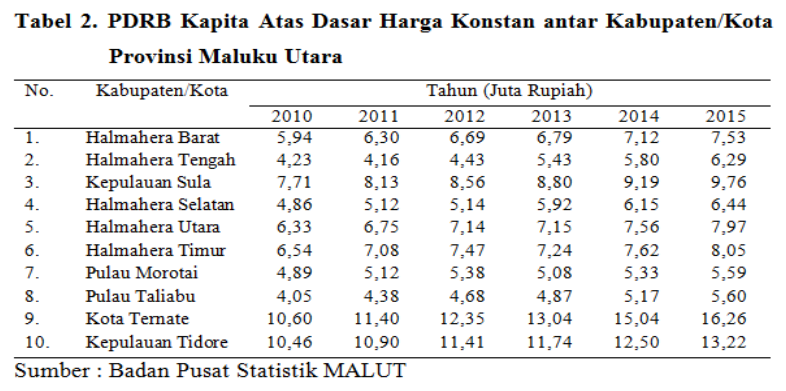




\section{Pertumbuhan Ekonomi Kabupaten/Kota Maluku Utara}

Pertumbuhan ekonomi antar Kabupaten/Kota di Maluku Utara terjadi karena adanya kenaikan pendapatan masyarakat yang diperoleh melalui kekayaan sumber daya alam, akumulasi modal, pertumbuhan penduduk dan tenaga kerja serta kemajuan teknologi. Sumber daya alam yang melimpah menyebabkan terjadinya pertumbuhan ekonomi, karena dengan adanya sumber daya alam tersebut maka hasil-hasil alam dapat diolah oleh para tangan tenaga kerja sehingga menambah penghasilan bagi daeranya dan berpengaruh pada pertumbuhan ekonomi daerahnya. Akumulasi modal terjadi karena sebagian pendapatan masyarakat ditabung dan diinvestasikan dengan tujuan memperbesar output dikemudian hari. Pertumbuhan penduduk dan tenaga kerja merupakan faktor positif dalam merangsang terjadinya kenaikan pertumbuhan ekonomi karena jumlah tenaga kerja produktif berpengaruh dalam pengelolaan sumber daya daerahnya sehingga dapat meningkatkan pertumbuhan ekonomi. Sedangkan kemajuan teknologi dapat meningkatkan hasil produksi suatu daerah (BPS MALUT, 2014).

Pada Tabel 3 disajikan data pertumbuhan ekonomi Kabupaten/Kota di Maluku Utara. Berdasarkan angka-angka tersebut dapat terlihat secara signifikan bahwa pertumbuhan ekonomi pada masing-masing daerah ini memiliki keragaman yang berpengaruh terhadap pembangunan ekonomi di Maluku Utara.

\begin{tabular}{|c|c|c|c|c|c|c|c|}
\hline \multirow[t]{2}{*}{ No. } & \multirow[t]{2}{*}{ Kabupaten/Kota } & \multicolumn{6}{|c|}{ Tahun (Juta Rupiah) } \\
\hline & & 2010 & 2011 & 2012 & 2013 & 2014 & 2015 \\
\hline 1. & Halmahera Barat & 5,24 & 6,32 & 6,41 & 8,57 & 6,03 & 6,37 \\
\hline 2. & Halmahera Tengah & 6,12 & 6,5 & 6,83 & 7,62 & 8,17 & 8,32 \\
\hline 3. & Kepulauan Sula & 5,00 & 5,64 & 5,66 & 8,09 & 5,6 & 6,43 \\
\hline 4. & Halmahera Selatan & 5,42 & 5,49 & 5,8 & 5,85 & 5,07 & 5,64 \\
\hline 5. & Halmahera Utara & 5,61 & 7,71 & 6,86 & 7,27 & 6,93 & 7,01 \\
\hline 6. & Halmahera Timur & 5,42 & 8,96 & 6,09 & 6,1 & 6,36 & 7,1 \\
\hline 7. & Pulau Morotai & 6,21 & 5,04 & 5,15 & 5,51 & 5,65 & 5,88 \\
\hline 8. & Pulau Taliabu & 5,74 & 8,19 & 7,18 & 7,36 & 7,54 & 8,33 \\
\hline 9. & Kota Temate & 6,8 & 8,77 & 9,77 & 7,3 & 8,39 & 8,71 \\
\hline 10. & Kepulauan Tidore & 5,35 & 6,76 & 6,13 & 6,88 & 7,76 & 7,98 \\
\hline
\end{tabular}

Data yang diperoleh dari Badan Pusat Statistik Provinsi Maluku Utara menunjukan angka pertumbuhan ekonomi antar Kabupaten/Kota dipengaruhi oleh ketersedian sumber daya alam yang ada pada masingmasing daerahnya. Misalnya tahun 2014 pertumbuhan ekonomi Halmahera Barat sebesar 6,03\% apabila dibandingkan dengan tahun 2013 sebesar 8,57\% menunjukan kecilnya kenaikan angka pertumbuhan ekonomi diduga disebabkan karena tidak adanya panen untuk komoditi cengke yang berpengaruh besar terhadap pertumbuhan ekonomi (BPS MALUT, 2014).

\section{Disparitas Pembangunan Ekonomi di Provinsi Maluku Utara}

Selain dianalisis dengan menggunakan alat analisis Indek Williamson, maka diperoleh hasil sebagai beikut:

Tabel 4. Indeks Williamson Pengukur Ketimpangan Pembangunan Ekonomi Antar Wilayah di Provinsi Maluku Utara

\begin{tabular}{cc}
\hline Tahun & Indeks Williamson \\
\hline 2010 & 0,25 \\
2011 & 0,25 \\
2012 & 0,26 \\
2013 & 0,26 \\
2014 & 0,27 \\
2015 & 0,28 \\
\hline
\end{tabular}

Indeks Williamson 2015 sebesar 0,28 artinya kecenderungan terjadi disparitas pembangunan ekonomi paling tinggi dibandingkan dengan tahun-tahun sebelumnya. Kondisi ini jauh berbeda atau hampir sama dengan tahun-tahun sebelumnya. Kondisi ini disebabkan karena produksi padi sawa dengan jumlah investasi dari tiap Kabupaten/Kota mengalami peningkatan yang berbeda yakni dengan rata-rata sekitar 1,605 milyar rupiah sehingga menyebabkan terjadinya disparitas pembangunan ekonomi antar Kabupaten/Kota karena kesejahtaraan masyarakat akan terlihat apabila dana diinvestasikan untuk kebutuhan dimasa yang akan datang maupun dalam pembangunan ekonomi daerahnya. Selain itu juga kecenderungan terjadinya disparitas di tahun 2015 yang makin meningkat dengan angka 0,28 dikarenakan pertumbuhan ekonomi antar Kabupaten/Kota di Maluku utara didominasikan sektor pertanian dengan presentase sebesar $16,03 \%$ diikuti oleh kontribusi jasa-jasa sebesar $14,02 \%$ dan kontribusi sektor perdagangan, hotel dan parawisata sebesar $13,44 \%$ (BPS MALUT, 2015). 
Indeks Williamson tahun 2014 sebesar 0,27 artinya kecenderungan terjadinya disparitas pembangunan ekonomi diantaranya karena produksi padi sawah didominasi oleh Kabupaten/Kota Halmahera Utara dan Halmahera Selatan (BPS MALUT, 2014).

Indeks Williamson tahun 2013 sebesar 0,26 disebabkan karena produksi padi sawa didominasi oleh Kabupaten Halmahera Utara dan Halmahera Selatan selain itu adanya perbedaan jumlah tenaga kerja dari tiap Kabupaten/Kota yang menyebabkan pengelolan sumber daya alam dari tiap Kabupaten/Kota mengalami kesenjangan (BPS MALUT, 2013).

Pada tahun 2012 Indeks Williamson 0,26 memiliki angka relative sama dengan tahun 2011 dan 2010 penyebab dikarenakan perekonomian yang diperoleh dari tiap Kabupaten/Kota dipengaruhi sektor parawisata melalui beragamnya para tamu asing yang masuk ke tiap daerah Kabupaten/Kota sehingga menyebabkan pendapatan daerah meningkat melalui sektor parawisata dan berdampak pada masalah kesenjangan pembangunan ekonomi (BPS MALUT, 2012).

Indeks Williamson tahun 2011 dengan angka 0,25 sama artinya kecenderungan terjadinya disparitas dikarenakan oleh produksi padi sawah yang tinggi pada Kabupaten Halmahera Utara dan Halmaheta Selatan (BPS MALUT, 2011).

Indeks Williamson tahun 2010 sebesar 0,25 artinya perekonomian di tahun 2010 mengalami kesenjangan karena produksi padi sawah didominasi oleh Kabupaten Halmahera Utara dan Halmahera Selatan sehingga kecenderungan terjadi disparitas makin nampak (BPS MALUT, 2010).

Terjadi ketimpangan pembangunan ekonomi di Maluku Utara disebabkan karena beberapa faktor di antaranya yakni perbedaan hasil-hasil alam seperti pertanian, perbedaan kondisi demografi seperti kepadatan penduduk, pendidikan, kesehatan perbedaan kualitas tenaga kerja, perbedaan nilai indeks pembangunan manusia, serta perbedaan fasilitas umum seperti transportasi dan komunikasi, hotel dan parawisata di tiap Kabupaten/Kota Provinsi Maluku Utara.

Ketimpangan tersebut misalnya dari segi ketenagakerjaan pada tahun 2013 tingkat pengangguran di Kabupaten Kepulauan sula masih cukup tinggi yang disebabkan karena tenaga kerja yang tersedia tidak sesuai dengan kualifikasi dan lapangan kerja yang tersedia sementara di Kabupaten Halmahera Timur pada tahun 2013 mengalami penurunan angka pengangguran karena sebagian besar masyarakat Haltim bekerja pada lapangan kerja yang sesuia dengan bidangnya dengan tenaga kerja yang sesuai dengan kualifikasi lapangan kerja yang tersedia.

Indeks Pembangunan Manusia di Kepulauan Tidore mengalami peningkatan selama tahun 2011-2013 yang didukung oleh kesehatan, pendidikan dan ekonomi masyarakat yang ada meskipun dearah ini masih tertinggal dengan Kabupaten/Kota lain namun tingkat IPM Ternate dikatankan cukup baik dengan IPM pada tahun 2012 berjumlah 60,71 meningkat menjadi 73,30 pada tahun 2013 sehingga PDRB per kapita mengalami peningkatan dari tahun 2011-2013, meningkat dari 162,02 milyar rupiah menjadi 210,61 milyar rupiah dengan kontribusi terbesar dari sektor pertanian yaitu $11,42 \%$. Sementara di Kabupaten/Kota Kota Ternate, tingkat IPM lebih tinggi dibandikan Ternate, dimana IPM Kota Ternate tahun 2012 mencapai 54,13 meningkat pada tahun 2014 senilai 64,77. Angka ini didorong oleh angka harapan hidup dari masyarakat Ternate. Seiring dengan meningkatnya IPM Kepulauan Tidore maka diikuti oleh peningkatan perekonomian dari PDRB ADHK meningkat 3,72 juta hingga 5,16 juta dari tahun 2013-2014 yang didukung oleh kontribusi terbesar yakni sektor pertanian.

Fasilitas seperti hotel dan parawisata di Kota Ternate mengalami peningkatan prendapatan karena pembangunan fasilitas seperti hotel dan parawisata di kota ini mampu menggalakkan kegiatan ekonomi karena merupakan daerah tujuan wisata di 
Maluku Utara yang di pilih sebagai baik dalam skala nasional maupun skala internasional. Sejak Tahun 2012 Ternate sukses dalam melaksanakan kegiatan wisatanwan seperti digelar berbagai event parawisata seperti Legu Gam di Ternate menjadi multiplier effect bagi sektor-sektor lain di mana dapat menggerakkan dan mengembangkan perekonomian sehingga tahun 2013 - 2014 PDRB ADHB Kota Ternate mengalami peningkatan 13,2 kali lipat yang didukung oleh kontribusi terbesar dari sektor perdagangan, restoran, dan hotel. Sementara untuk fasilitas hotel dan parawisata di Kepulauan Tidore mengalami peningkatan jumlah fasilitas namun mengalami penurunan wisman dimana pada tahun 2012 mencapai 1,102 orang sementara pada tahun 2013 hanya 5,46 orang. Hal ini menjadi perhatian pemerintah Kota Kepulauan untuk lebih menggalakkan program parawisata agar banyak wisatawan yang berkunjung dan pertumbuhan ekonomi di sektor parawisata dapat lebih meningkat di bandingkan Kota Ternate. Data tersebut dapat dilihat bahwa potensi masingmasing daerah yang ada di Provinsi Maluku Utara memiliki perbedaan yang signifikan sehingga mempengaruhi proses pembangunan ekonomi.

Oleh karena itu adanya hal-hal tersebut maka proses pembangunan antar wilayah di Provinsi Maluku Utara terus mengalami ketimpangan yang secara jelas dapat tercermin dalam angka PDRB per kapita dan pertumbuhan ekonomi yang terus mengalami kesenjangan.

\section{KESIMPULAN DAN SARAN}

\section{Kesimpulan}

Berdasarkan Hasil Penelitian dapat disimpulkan bahwa Disparitas pembangunan ekonomi tertinggi berada pada tahun 2015. Disparitas ini karena perbedaan pendapatan per kapita dan pertumbuhan ekonomi yang dilatar belakangi oleh beragamnya potensi dan kekayaan alam Kabupaten/Kota di Provinsi Maluku Utara.
Berdasarkan Analisis dengan menggunakan Indeks Williamson bisa diketahui bahwa kesenjangan pembangunan ekonomi di Provinsi Maluku Utara tidak terlalu tinggi, namun ada kecenderungan setiap tahun kesenjangan pembangunan ekonomi terus mengalami peningkatan. Selain itu terdapat beberapa Kabupaten/Kota yang bisa dikatakan masih tertinggal karena memiliki nilai indeks di bawah rata-rata Kabupaten/Kota dan beberapa Kabupaten/Kota sebagai daerah yang maju karena memiliki nilai indeks di atas rata-rata.

\section{Saran}

1. Diperlukan kebijakan dari Pemerintah Provinsi dan Pemerintah Kabupaten/Kota guna menanggulangi masalah kesenjangan pembangunan ekonomi di Provinsi Maluku Utara agar proses pembangunan antar Kabupaten/Kota lebih berimbang dan pertumbuhan ekonominya lebih merata.

2. Perlu diadakan peningkatan pembangunan ekonomi yang berbasis pada pemanfatan sumber daya alam yang ada pada masingmasing daerah.

\section{DAFTAR PUSTAKA}

Badan Pusat Statistik MALUT. 2010. Malut Dalam Angka. Ternate : BPS MALUT.

Badan Pusat Statistik MALUT. 2011. Malut Dalam Angka. Ternate : BPS MALUT.

Badan Pusat Statistik MALUT. 2012. Malut Dalam Angka. Ternate : BPS MALUT.

Badan Pusat Statistik MALUT. 2013. Malut Dalam Angka. Ternate : BPS MALUT.

Badan Pusat Statistik MALUT. 2014. Malut Dalam Angka. Ternate : BPS MALUT.

Badan Pusat Statistik MALUT 2015. Malut Dalam Angka. Ternate : BPS MALUT.

Irawan S. 2012. Konsep Disparitas Pembangunan Ekonomi. Yogyakarta : Liberty. 
Sirojuzilam. 2008. Disparitas Ekonomi dan Pengembangan Regional. Medan : Pustaka Bangsa Press.

Sjafrizal. 2012. Ekonomi Wilayah dan Perkotaan. Padang : PT Rajagrafindo Persada Indonesia. 